\title{
ANÁLISE DE CRITÉRIOS PARA A ELABORAÇÃO DA POLÍTICA CRIMINAL
} PELO PARLAMENTO BRASILEIRO

\author{
José Wilson Ferreira Lima ${ }^{1}$
}

RESUMO: Trata-se de pesquisa teórico-argumentativa que objetiva analisar se há e quais seriam os critérios empregados pelo Parlamento brasileiro para definir propostas legislativas que se enquadrariam e atenderiam às necessidades da política criminal, entendendo que a produção legislativa se confunde com a política criminal, quase sempre voltada para satisfazer às necessidades de ocasião diante, principalmente, das especulações dos veículos de comunicação e também para dar respostas rápidas às crises de violências que alimentam os elevados índices de criminalidade. Metodologicamente, o estudo analisará caso específico de projeto de lei, que servirá como referencial empírico.

Palavras-Chave: Política Criminal. Atividade Legislativa. Discricionariedade. Criminalidade. Populismo Penal.

\section{ANALYSIS OF STANDARDS FOR THE ELABORATION OF CRIMINAL POLICY BY BRAZILIAN PARLIAMENT}

\begin{abstract}
It's theoretical-argumentative research that aims to analyze if there are and what would be the standards used by the Brazilian Parliament to define legislative proposals that would adjust and attend the needs of the criminal policy. It is understanding that the legislative production has been confused with the criminal policy, almost always focus for satisfying of the occasion needs, especially with regard to the speculation of the media and also to respond quickly to the violence crisis that fuels high crime rates. Methodologically, the study will analyze a specific case of the law project, that will serve as empirical reference.
\end{abstract}

Keywords: Criminal Policy. Legislative Activity. Discretionarily. Criminality. Penal Populism.

\footnotetext{
${ }^{1}$ Doutorando em Direito pelo UniCEUB e Mestre em Direito Constitucional. E-mail: wferreiraster@gmail.com.
} 


\section{INTRODUÇÃO}

O Parlamento brasileiro, composto pelo Senado Federal e pela Câmara dos Deputados, é o ambiente político mais importante e central para o desenvolvimento da política criminal, isso porque é dele que devem partir as diretrizes legais que condicionam o exercício do poder punitivo nos limites definidos pela Constituição Federal. Assim, ao estabelecer e desenvolver uma política criminal, o Parlamento tem a missão de cumprir a Constituição numa clara relação de poder, que se manifesta não apenas como atividade legislativa, mas também de modo a tornar efetivos os comandos constitucionais especialmente dirigidos para a proteção dos direitos e das garantias fundamentais individuais.

Nessa medida, os arranjos institucionais que envolvem a atuação parlamentar, considerados não apenas individualmente, isto é, os que decorrem dos ajustes levados a efeito entre senadores e deputados federais, como também os dos blocos e bancadas partidários, os das comissões e, enfim, os dos plenários de ambas as Casas Legislativas, são técnicas usuais próprias da expertise político-partidária, que se mostram necessárias como forma de angariar adesões e, consequentemente, os votos exigidos para a aprovação das mais diversas propostas apresentadas sob a forma de projetos de leis.

No entanto, a produção da política criminal não pode nem deve ser considerada apenas como prática usual do Parlamento, isto é, como rotina legislativa que, redundantemente, cumpriria sua função constitucional pela simples aprovação ou rejeição dos projetos apresentados. A política criminal não pode ser reduzida ao mero exercício do poder punitivo ou à simples relação de poder externada pelo Parlamento em cumprimento às suas competências definidas pela Constituição Federal.

Partindo desse ponto, o objetivo do presente estudo é analisar a atuação parlamentar no que concerne com a produção da política criminal brasileira nos limites da Constituição Federal e dos possíveis arranjos institucionais que condicionam o exercício dessa atividade pública. Para tanto, o problema que orientará o desenvolvimento da pesquisa consistirá em definir se há e quais seriam os critérios empregados pelo Parlamento para definir as propostas que se enquadrariam e atenderiam às necessidades imediatas de uma política criminal.

Como, no entanto, a plataforma da atuação política e legislativa é muito vasta, um recorte estratégico nesse campo de abordagem é medida de ordem didática que se impõe. 
Logo, para atingir esse objetivo, o método empregado na pesquisa consistirá em analisar caso específico de projeto legislativo como referencial empírico, que por sua vez será cotejado com a atual linha teórico-argumentativa sobre política criminal. Trata-se, portanto, de pesquisa centrada na análise crítica que assume como pressuposto a condição do Estado de Direito como fundamento para a atuação parlamentar e o desdobramento desta em ações práticas que qualifiquem as políticas públicas resultantes, de onde a política criminal é uma das mais importantes e complexas formas de produção política e legislativa.

Justifica-se a relevância do desenvolvimento deste estudo em razão da atual conjuntura institucional e política que envolve a atuação das instituições do Estado brasileiro, notadamente circunstanciadas pelos seguintes fatores: i) a convergência do clamor público ante aos elevados índice de criminalidade, ii) o discurso político aberto e insistente quanto à necessidade de respostas rápidas e eficazes à violência, que marca o cotidiano em todo o território brasileiro, iii) a vigência do Estado de Intervenção, que teve como fundamento a situação de descontrole em níveis alarmantes da segurança pública no Estado do Rio de Janeiro, e, especialmente, iv) o fator político, que se reforça e se alimenta do discurso em torno da adoção de políticas criminais com maior rigor punitivo, como mecanismo sedutor e atrativo do capital político.

O referencial empírico que será objeto de exame compreende duas produções legislativas: i) a Lei n. 13.654, de 23 de abril de 2018 (BRASIL, 2018a), que introduziu alterações no Código Penal brasileiro consistentes, entre outras medidas, em revogar o inciso I, do $\S 2^{\circ}$, do art. 157 e em criar o $\S 2^{\circ}$-A, cujo inciso I passou a dispor sobre a circunstância de aumento da pena do referido crime, quando praticado mediante o emprego exclusivo de "arma de fogo", e ii) o Projeto de Lei do Senado (PLS) n. 279 de 2018, que restabelece no crime de roubo a causa de aumento de pena quando houver "emprego de arma":

\footnotetext{
Crime de Roubo - Redação Anterior:

Art. 157 - Subtrair coisa móvel alheia, para si ou para outrem, mediante grave ameaça ou violência a pessoa, ou depois de havê-la, por qualquer meio, reduzido à impossibilidade de resistência:

Pena - reclusão, de quatro a dez anos, e multa.

$\S 2^{\circ}$ - A pena aumenta-se de um terço até metade:

I - se a violência ou ameaça é exercida com emprego de arma (Revogado pela Lei n. 13.654/2018) (BRASIL, 1940).

Crime de Roubo - Redação Atual:
} 
Art. 157 - Subtrair coisa móvel alheia, para si ou para outrem, mediante grave ameaça ou violência a pessoa, ou depois de havê-la, por qualquer meio, reduzido à impossibilidade de resistência:

Pena - reclusão, de quatro a dez anos, e multa.

$\S 2^{\circ}$-A A pena aumenta-se de $2 / 3$ (dois terços):

I - se a violência ou ameaça é exercida com emprego de arma de fogo (Incluído pela Lei n. 13.654/2018) (BRASIL, 1940).

Projeto de Lei do Senado (PLS) n. 279 de 2018:

O CONGRESSO NACIONAL decreta:

Art. $1^{\circ} \mathrm{O}$ art. $157, \S 2^{\circ}$, do Decreto-Lei n. 2.848, de 7 de dezembro de 1940 - Código Penal, passa a vigorar acrescido do seguinte inciso VII:

"Art. 157

$\S 2^{\circ}$ A pena aumenta-se de um terço até metade:

VII - se a violência ou ameaça é exercida com emprego de arma".

Art. $2^{\circ}$ Esta Lei entra em vigor na data de sua publicação.

(BRASIL, 2018b).

\section{CONSIDERAÇÕES GERAIS SOBRE A POLÍTICA CRIMINAL}

"Política criminal, como a própria expressão evidencia, é política e esta é indissociável da discussão a respeito dos lindes de nossa democracia" (SUXBERGER, 2013, p. 350). De fato, não se pode avançar no ambiente da análise crítica sobre a política criminal sem considerar sua principal marca e característica, isto é, a de ser fruto de acordos políticos, que envolvem os mais diversos interesses que se contextualizam no amplo espectro da democracia. Tudo isso, sem dúvida, faz com que o sucesso ou o fracasso de uma política dita criminal não se atribua com exclusividade ao Parlamento, mas antes às contingências da realidade social e econômica, tanto que, atualmente, se discute enfaticamente sobre a ideia de que a superação da criminalidade em alguns contextos não faz mais sentido, de forma que se torna ilógico desenhar a política criminal operando sobre o infrator individual, a partir de teses sobre as causas do delito, pretendendo incidir sobre as disfunções que geram essas condutas criminosas (WERMUTH, 2017, p. 2047). Sob essa óptica, se poderia argumentar que, embora fatores sociológicos e econômicos possam afetar a efetividade da política criminal, desenhada e posta em vigor pelo Parlamento, este, ainda assim, estaria resguardado pela democracia e isto minimizaria ou até mesmo excluiria sua responsabilidade diante de eventuais fracassos verificados.

Entretanto, a questão que se coloca é a de definir se há e quais seriam os critérios a serem empregados pelo Parlamento para apresentar propostas que se enquadrariam e atenderiam às necessidades imediatas de uma política criminal no momento de sua produção, oportunidade em que a análise de eventuais fatores sociológicos e econômicos poderiam (e 
deveriam) ser tratados já no momento de sua articulação, no próprio ambiente políticoparlamentar. Essa discussão se reveste de especial relevância na medida em que a ordem jurídico-constitucional reservou ao Estado o monopólio do exercício legítimo da violência, de modo que as decisões estatais com caráter de obrigatoriedade devem ser atribuídas a textos de normas de "forma convincente" (MORAIS, 2016, p. 32).

Isso significa que a política criminal não será, necessariamente, sempre uma opção ou um modo de agir imune a falhas ou fracassos, mas deverá ser decisão rigorosamente pautada nos limites permitidos pela ordem jurídica vigente, especialmente quanto aos balizamentos impostos pela Constituição Federal, de modo que sua "forma convincente" deverá ser consequência de estudos especialmente orientados sobre a necessidade, o conteúdo, a adequação, a oportunidade, a constitucionalidade e a legalidade dos atos e das decisões que a integrarem. Também por conta dessas condicionantes, a política criminal não pode ser articulada como mero exercício político de respostas rápidas, e por vezes infundadas, aos problemas generalizados decorrentes da falta de controle sobre a criminalidade. Portanto, como política pública, a política criminal deve ser suportada pelos preceitos constitucionais e atender aos princípios da igualdade, razoabilidade, proporcionalidade, legalidade, impessoalidade, motivação e resguardar o mínimo existencial e os direitos fundamentais (MURDA, 2015, p. 41). Espera-se, com isso, que se tenha uma sistematização teórica para a produção e a abordagem das políticas públicas, de modo a contribuir para "a criação de fórmulas de organização e estruturação do poder público capazes de melhorar sua intervenção e acelerar o processo de modernização, de redução da desigualdade e de inclusão social" (BUCCI, 2013, p. 37), o que igualmente se espera da política criminal.

Ademais, sendo a política criminal parte integrante do todo denominado política estatal, ela depende não apenas do êxito das diversas políticas públicas, como também as pressupõem, sem o que não haveria como se definir ou se efetivar (MORAES, 2006, 411). Ao lado disso surge, enfim, a perspectiva das políticas públicas eficientes, de onde a política criminal eficiente é aquela que se insere no plano do controle penal moderno e da ordem social, de modo a com ela contribuir, conservando-a e reproduzindo-a (ANDRADE, 2009, p. 14-15).

Com isso, concordando com a afirmação inicial, Torrens sustentou que o locus preferencial responsável pela produção de leis que reflitam as bases da atuação governamental 
é o Poder Legislativo (2013, p. 192), de onde a política criminal emerge sob a forma de tomada de decisões (decision making) relacionadas com o controle da criminalidade, cujos objetivos básicos são regular e minimizar a soma dos custos sociais decorrentes das práticas criminosas e dar as respostas da sociedade ao crime, além de distribuir esses encargos de maneira justa entre as partes envolvidas, isto é, infratores, vítimas, contribuintes etc. (AROMAA, 2014, p. 80).

Mas, esse ponto de vista aponta para outra face de abordagem da política criminal, que é a que se refere à coexistência de i) uma legislação universalista e mais igualitária, cujo objetivo é o de ampliar o conjunto dos direitos e das garantias fundamentais, com ii) uma política de recrudescimento do sistema penal e punitivo, como resultante da aprovação de políticas de segurança pública e justiça criminal (CAMPOS, 2014, p. 316). Aliás, nesse contexto, Anabela Rodriguez destacou que a criminalidade tem sido a principal causa para que a política criminal esteja sendo reduzida a não mais do que uma "política criminal de segurança" (2003, p. 185).

Diante de todo esse quadro, que caracteriza o amplo espectro da política criminal brasileira, entende-se necessário que se adote posição mais objetiva em relação às propostas legislativas, de modo a estabelecer uma agenda que seja condizente, por exemplo, no âmbito da política criminal, com as propostas de alternativas penais, contrapondo-se à inflação legislativa meramente quantitativa e midiática (BALLESTEROS, 2016, p. 5). Ou seja, impõese rigor na indicação da necessidade de que haja adequação da política criminal aos instrumentos de governança no âmbito da política pública, de modo a ajustar a "política que guarda relação com parâmetros de eficácia e efetividade exigidos para uma política pública" (BRASIL, 2015a, p. 5).

É importante frisar que as propostas para reduzir o crime e promover a segurança dão importância às medidas para melhorar a eficiência e a eficácia do chamado sistema de justiça criminal, que formalmente resolve apenas uma pequena parte da totalidade dos crimes e apresenta limitações significativas no impacto que suas medidas podem produzir sobre o crime em geral (GARSIDE, 2004, p. 5). Nesse sentido, não se pode olvidar que a principal contribuição para o crescimento da onda do punitivismo penal vem da insegurança pública conduzida, em boa medida, pela mídia em relação aos crimes e criminosos, abordada por meio de iniciativas governamentais que embora sejam visíveis são efetivamente vazias 
(MONTEROSSO, 2009, p. 14). Além disso, a todo um conjunto de fatores negativos que aflora do meio político e dá suporte para o populismo punitivo:

[...] interesses políticos do Estado no combate à criminalidade, muitas vezes na forma de um lamentável "populismo punitivo", se mantêm em forte e contínua tensão com os direitos e as garantias fundamentais, acabando, não raramente, por prevalecer sobre esses, quer gerando pequenas violações a princípios e regras fundamentais, geralmente, percebidos e combatidos apenas em âmbito técnico, quer gerando atos de explícita e acintosa arbitrariedade (D’ÁVILA, 2008, p. 485).

A par desses esclarecimentos introdutórios, não custa lembrar que, enquanto as instituições liberais tendem a restringir a punição estatal em nome de um governo limitado e dos direitos dos indivíduos, as instituições ditas democráticas tendem a punir de acordo com as preferências das maiorias, sejam elas quais forem (GARLAND, 2013, p. 507). Por conseguinte, sendo o Parlamento uma das instituições democráticas do País, impõe-se questionar que critérios ou fundamentos de política criminal serviram de base ou justificativa para a revogação do inciso I, do $\S 2^{\circ}$, do art. 157, do Código Penal, operando-se, com isso, a extirpação do ordenamento jurídico da causa de aumento da pena do crime de roubo, quando a violência ou a grave ameaça tiver sido exercida mediante o "emprego de arma" que não seja "arma de fogo".

\section{EXAME DA LEI N. 13.654/2018}

A referida lei foi sancionada e publicada no Diário Oficial da União de 24 de abril de 2018, sendo produto do Projeto de Lei do Senado (PLS) n. 149 de 2015, que em sua redação original determinava a revogação do inciso I, do $\S 2^{\circ}$, do art. 157, do Código Penal (BRASIL, 2015b). Nesse primeiro momento, convém situar que a referida disposição revogada estava presente do Código Penal brasileiro desde sua edição em dezembro de 1940. Ou seja, a diretriz normativa que permitia o aumento da pena do crime de roubo, na proporção de $1 / 3$ (um terço) até metade, nos casos em que a violência ou ameaça tivesse sido exercido com "emprego de arma", contava com pouco mais de 77(setenta e sete) anos de existência e validade jurídica.

A tecnológica jurídica, que compreende as áreas ou campos de conhecimentos definidos como doutrina e jurisprudência, sempre admitiu de forma consistente e reiterada que a expressão "emprego de arma", articulada como circunstância de aumento da pena do crime de roubo, teve seu fundamento no maior grau de perigo que o emprego de arma 
envolve, motivo pelo qual é indispensável que o instrumento usado tenha idoneidade para ofender a incolumidade física da vítima (FRAGOSO, 1988, p. 350). Ademais, por armas compreendem-se diversos artefatos ou instrumentos utilizados, em regra, para o ataque ou a defesa, sendo que em razão de sua natureza elas podem ser qualificadas em grupos distintos. Desse modo, são armas próprias as de fogo, como revólveres, pistolas, fuzis etc., e são armas brancas as facas, estiletes etc., além dos explosivos em geral (MIRABETE, 2003, p. 1204).

Com efeito, tendo em vista o maior risco que a arma pode causar à integridade física da vítima do crime de roubo, essa circunstância passou a ser um dos fatores, e talvez o mais comum, para se autorizar o aumento da pena desse crime:

Recurso ordinário em habeas corpus. Penal. Roubo triplamente qualificado. Impetração não conhecida pelo Superior Tribunal de Justiça por ser substitutiva de recurso especial. Entendimento que não se coaduna com o entendimento da Corte. Precedentes. Majoração decorrente das qualificadoras. Decisão concretamente fundamentada em circunstâncias desfavoráveis. Aumento justificado e dentro dos limites discricionários do juiz. Precedentes. Emprego de arma branca. Qualificação corretamente reconhecida. Recurso não provido.

4. A utilização de facas (armas brancas ou impróprias) tem inegável potencial lesivo, visto que essa qualidade integra a própria natureza do artefato, reduzindo a possibilidade de resistência da vítima. Precedente (BRASIL, 2014, p. 1).

Mesmo diante de tais considerações, o mencionado PLS n. 149/2015, em sua redação inicial, não dispôs de nenhuma justificativa quanto à revogação do dispositivo em exame, embora se possa vislumbrar que o foco central do projeto tenha sido a incorporação de novo dispositivo com o qual se passaria a ter o aumento da pena do crime de roubo em 2/3 (dois terços) nos casos em que a violência ou ameaça venha a ser exercida mediante o emprego de "arma de fogo", além do fato recorrente quanto à prática de roubo com o emprego de explosivos. Entretanto, mesmo considerando essa realidade, a relatoria do projeto não logrou justificar de forma clara as razões que levaram o Parlamento brasileiro a revogar, expressamente, o inciso I, do $\S 2^{\circ}$, do art. 157, do Código Penal. As razões da relatoria se limitaram, basicamente, nas considerações de que:

É preciso, portanto, aperfeiçoar o tipo penal previsto no art. 157 do $\mathrm{CP}$ e, consequentemente, cominar uma pena mais severa ao criminoso que pratica o roubo, se valendo de explosivos ou materiais semelhantes. É importante que a Lei penal defina o fato criminoso o mais objetivamente possível, fazendo distinção entre condutas mais e menos graves. A proposta em exame é exatamente nesse sentido (BRASIL, 2015b, p. 1-2).

Com esses fundamentos, foi apresentado o relatório legislativo quanto ao PLS n. 149/2015 em julho de 2015, o qual somente em 8 de novembro de 2017 teve nova 
movimentação na Comissão de Constituição, Justiça e Redação do Senado Federal. Embora o projeto tenha sido mantido inerte, sem receber qualquer movimentação por um período superior a 2 (dois) anos no Senado, este foi aprovado e encaminhado à Câmara dos Deputados em 23 de novembro de 2017, ou seja, apenas 15 dias após a apresentação do relatório, não tendo a Casa Revisora apresentado qualquer questionamento ou mesmo aperfeiçoado o projeto original, de modo a trazer fundamentos consistentes quanto à revogação do inciso I, do $\S 2^{\circ}$, do art. 157, do Código Penal.

O fato é que, subsequentemente, o projeto foi sancionado e transformado na Lei $\mathrm{n}$. 13.654/2018, de 24 de abril de 2018, cuja principal consequência jurídica produzida em relação ao mencionado dispositivo revogado foi a redução da pena aplicada ao infrator, como consequência lógica da desconstituição da majorante penal. Nesse sentido, o caráter benéfico da lei nova deve favorecer todos os apenados que praticaram crimes de roubo mediante o "emprego de armas" ditas brancas, sejam elas próprias ou impróprias. Assim, atendendo-se à diretriz introduzida pela Lei n. 13.654/2018, o Superior Tribunal de Justiça reconheceu e aplicou o comando da lei em exame para o fim de determinar a redução da pena em face do caso concreto levado à sua alçada jurisdicional:

DIREITO PENAL. AGRAVO REGIMENTAL. ROUBO CIRCUNSTANCIADO. SENTENÇA. DOSIMETRIA. EMPREGO DE ARMA BRANCA. NOVATIO LEGIS IN MELLIUS. LEI 13.654/18. RECURSO PROVIDO.

1. A Lei 13.654/18 extirpou o emprego de arma branca como circunstância majorante do delito de roubo. Em havendo a superveniência de novatio legis in mellius, ou seja, sendo a nova lei mais benéfica, de rigor que retroaja para beneficiar o réu (art. $5^{\circ}, \mathrm{XL}$, da CF/88).

2. Recurso provido a fim de reduzir a pena imposta ao recorrente ao patamar de 8 anos, 1 mês e 10 dias de reclusão, mais o pagamento de 17 dias-multa, mantidos os demais termos da condenação (BRASIL, 2018c).

A exclusão dessa causa de aumento, além de atuar diretamente no montante da pena aplicada, reduzindo-a, pode produzir efeitos também quanto ao curso da prescrição e do regime prisional, atendendo-se às particularidades de cada caso. De qualquer modo, superado todo o processo legislativo que culminou com a edição da Lei n. 13.654/2018, novo projeto de lei foi apresentado pelo Senado Federal com o propósito único de restabelecer o aumento da pena do crime de roubo quando a violência ou a ameaça for exercida mediante o "emprego de arma”. Esse novo arranjo legislativo, contido no PLS n. 279, de 6 de junho de 2018, aprovado e encaminhado à Câmara dos Deputados, teve como justificativa a necessidade de atender "aos amplos reclamos de diversos aplicadores do direito" (BRASIL, 2018b). 
Todavia, não se constatou nem no PLS n. 149/2015 (revogou a causa de aumento), tampouco no PLS n. 279/2018 (busca restabelecer a causa de aumento) qualquer estudo rigorosamente fundamentado, segundo um juízo claro e explícito da técnica jurídica que justificasse a adoção de tais projetos frente à causa de aumento da pena do crime de roubo, que contava com mais de 77(setenta e sete) anos de existência e validade jurídica. Dito de outro modo, não havia em tais projetos "forma ou recurso convincente" para a adoção da medida legislativa, senão, apenas, o exercício da atividade política desvinculada de critérios, rumos ou valores persuasivos.

\section{POLÍTICA CRIMINAL E LEGALIDADE}

É entendimento pacífico de que crime é, em regra, um comportamento proibido pela lei, de modo que nenhum ato pode ser considerado em sua essência criminoso, independente de quão possa ser imoral ou prejudicial aos indivíduos, a menos que tenha sido criminalizado pela legislação (CARRABINE, 2009, p. 157). Assim, devido ao lógico-formal inspirado pelo princípio da legalidade estrita, não se pode agravar as consequências jurídicas de uma conduta definida como violadora da ordem jurídica sem o devido respaldo legal e sem que haja reprovação socialmente exigida. Nessa ordem, se, após mais de 77(setenta e sete) anos de existência e validade jurídica, a majorante do crime de roubo relativa com o "emprego de arma" foi revogada, essa mesma majorante não poderia ser "restabelecida" mediante a simples adoção de um projeto de lei que não contivesse fundamentação segura e consistente que justifique sua adoção.

Todavia, paradoxalmente, se a nova proposta, adotada com não mais de 60 (sessenta) dias após a publicação da lei que revogou expressamente o inciso I, do $\S 2^{\circ}$, do art. 157, do Código Penal, tivesse mesmo fundamentação segura e consistente para restabelecer a causa de aumento, é porque de modo algum havia fundamentação robusta, seja de ordem jurídica, política, econômica ou sociológica, que justificasse a pretérita revogação da aludida causa de aumento.

Entendendo que fatores sociais, econômicos, culturais, políticos etc., conjuntamente com outras variáveis circunstanciais, formam um inquestionável poder determinante do gerenciamento do comportamento humano individual e social (GUTIÉRREZ HINOJOSA, 2016, p. 18), restaria definir que razão, fator ou critério levou o legislador brasileiro, em meio 
à intensa onda de criminalidade que tem marcado o cenário social e político, a revogar o inciso I, do $\S 2^{\circ}$, do art. 157, do Código Penal, e, em menos de 60 (sessenta) dias, apresentar novo projeto de lei visando restabelecê-lo com o mesmo conteúdo, tudo isso considerado em face de duas circunstâncias que não podem ser ignoradas: i) o dispositivo revogado contava com mais de 3/4 de século de vigência plena no ordenamento jurídico-penal e ii) o dispositivo em questão garantia a majoração da pena do crime de roubo, no qual a vítima fosse colocada numa condição de maior perigo e vulnerabilidade quanto à sua incolumidade.

Como se sabe, a existência do direito penal e processual penal decorre da necessidade condicionada pelo Estado Constitucional de Direito, com a função de priorizar as garantias dos bens jurídicos, buscando a tutela judicial efetiva destes de acordo com a normatividade jurídica em vigor (BENAVIDES BENALCÁZAR; MORALES, 2017, p. 270), pois, embora contemporaneamente o crime deva ser expressão da legalidade estrita, admite-se sua peculiar condição de ser "um acontecimento que não requer nenhuma motivação ou disposição especial, nenhuma patologia ou anormalidade, e que se inscreve nas rotinas da vida econômica e social" (GARLAND, 1999, p. 66). Portanto, nessa medida, cumpre à política criminal tornar claros os parâmetros para o exercício do poder punitivo, assim como reforçar e proteger os direitos e as garantias fundamentais individuais.

Seguindo nessa perspectiva, o direito penal não deve ser considerado mero instrumento para o atingimento de qualquer objeto político, devendo ser empregado para criar o equilíbrio entre os princípios de envergadura constitucional, como o da liberdade e o da segurança (KUBICIEL, 2013, p. 35). Devido a isso, a visão ampla da política criminal deve ter correspondência com o que se deve entender pelo sistema penal, que compreende e integra, no plano normativo, as normas penais, as medidas de segurança e outras sanções de caráter penal, assim como as normas especiais quanto à aplicação da pena e sua execução (SUMALLA, 2007, p. 2). Nesse contexto, é correto admitir que a política criminal é antes parte da política que adota orientações e decisões, criminais e não criminais, legais e sociais, com as quais o Estado deve atuar contra o crime (QUINTERO OLIVARES, 2007, p. 48). Ademais, não se pode ignorar que temas recorrentes enfocados no contexto da política criminal contemporânea dizem respeito com os acontecimentos que a sociedade experimenta em seu cotidiano em relação ao crime e à desordem social (MORALES, 2012, p. 115). 


\section{POLÍTICA CRIMINAL E ORDEM JURÍDICA}

Sob outro ponto de vista, as ideias sociais e a história da filosofia do direito penal desempenharam significante papel nos estudos da política criminal, tanto que as atitudes, as crenças e as expectativas que tornaram essas ideias atraentes e persistentes se apresentam como foco de interesse para os estudos da política criminal (LACEY; SOSKICE; HOPE, 2017, p. 10), não sendo razoável que se abandonem esses critérios no momento da formulação de novos projetos de leis que se destinam a alterar tão significativamente a ordem jurídica vigente e estabilizada, sem justificativas ou motivações claras e convincentes. Correlato com essa perspectiva, está implícito no conceito de "populismo penal" que o público prefere as políticas punitivas no campo da justiça criminal, porque considera que elas são estáveis e duradouras e, inegavelmente, são eleitoralmente populares (JENNINGS, 2015, p. 4).

Diante de tais ponderações, não apenas pelo seu conteúdo argumentativo, mas também técnico que envolve a produção da política criminal num ambiente regido por uma ordem jurídica constitucionalmente estabelecida, é preciso ter em consideração que a criminalidade não é simples construção voltada de cima para baixo (top down) e imposta pelo sistema de justiça criminal ou, mais especificamente, desenhada pelo Parlamento; assim como também não é um processo ascendente que envolve certos atos ou comportamentos (bottom up), mas uma relação complexa entre diferentes fatores. Em face dessa natureza, o crime não pode ser redutível a um ato, nem pode ser enfocado como mero produto da reação social (MATTHEWS, 2009, p. 346). Por isso, a produção cambiante de leis que interfiram na seara do direito penal e nos demais setores do sistema de justiça criminal não podem ser concebidas como mero exercício da atividade legislativa, exigindo-se de seus elaboradores (law makers) a necessária ponderação e justificação, rígidas e consistentes, quanto às suas decisões, para que os produtos finais não sejam atos de questionável interesse e valor para a sociedade.

É importante observar que em termos práticos a noção de política criminal se associa fundamentalmente com o funcionamento do sistema penal, com o qual se confunde (SÁNCHEZ; VARGAS; PINZÓN, 2017, p. 45) e, devido a isso, permitir a elasticidade das decisões políticas que, num primeiro momento, revogam comandos normativos penais já consolidados e estabilizados e, em momento subsequente, restabelecem esses comandos, implica fragilizar e desacreditar o próprio sistema penal punitivo, sobre o qual a política 
criminal deveria atuar com o propósito de fortalecer as instituições da justiça criminal e a própria credibilidade do Parlamento.

Assumindo que a relação entre o direito e a política não é apenas um vínculo consequencial, mas também necessário para se manter a própria harmonia e higidez do ordenamento jurídico, não é desarrazoado que entre estes se estabeleça uma relação parasitária, pois, uma vez que a política pode se favorecer com o fato de que a decisão sobre a conformidade com o direito (por exemplo, o controle de constitucionalidade) será resolvido noutro sistema, o jurídico, é fato igualmente certo que o direito, enquanto elemento do sistema jurídico, se beneficiará com o uso da coação, mediante o emprego da força, que lhe será assegurado pelo sistema político (MACHADO, 2014, p. 54). Esse vínculo próximo, ou relação de interdependência e de mútua interferência, é positivo para a política e para o direito no contexto mais amplo da justiça criminal. Entretanto, assim como o direito não pode ser aplicado por qualquer das instâncias formais do sistema de justiça criminal sem que se tenha uma substancial fundamentação e amparo legal, a exemplo das decisões que impõem a condenação, a absolvição, a privação da liberdade etc., não pode a política criminal atuar no direito criando, revogando, restabelecendo normas que compõem o ordenamento jurídico etc., à revelia de criterioso processo e sem robusta fundamentação e adequação segundo as necessidades demandadas pelas sociedade.

De acordo com a perspectiva de abordagem da relação entre o direito e a política, a produção legislativa assume sentidos diferenciados para os sistemas político e jurídico, podendo compreender um viés instrumental ou meramente simbólico para o sistema político (MACHADO, 2013, p. 12). Mas, irremediavelmente, a produção legislativa, fruto da política criminal desorientada e sem fundamentos convincentes, pode produzir consequências na ordem social que não podem ser simplesmente corrigidas com mais produções legislativas. Ademais, qualquer que seja a proposta legislativa, ela deve ser coerente, seja em razão dos princípios constitucionais, seja do emprego dos meios acadêmicos disponíveis, como estudos, teses, estatísticas etc., tudo de modo a "fornecer ao Parlamento um instrumento de coerência da política criminal”, fazendo bom uso das palavras de Delmas-Marty (2004, p. 359). 


\section{O CONVENCIMENTO COMO CRITÉRIO PARA A ELABORAÇÃO DE POLÍTICAS CRIMINAIS}

Silva Sánchez distinguiu a política criminal segundo seu viés prático e teórico, entendendo que a prática dessa política integra um conjunto de atitudes empíricas, organizadas para o enfrentamento do crime e sua vertente teórica compõe-se de um conjunto de princípios que cumprem fornecer a base racional para o combate ao crime, cujo cerne da discussão deve ser o de determinar os meios racionais e os critérios de racionalidade (SILVA SÁNCHEZ, 2000, p. 21-22). Ao lado dessa diferenciação, tem-se que o processo de criação legislativa se ampliou consideravelmente, isso porque a produção legislativa no Brasil cresceu em escala, tornando-se prática recorrente e com repercussões negativas. Diz-se, devido a isso, que há uma infinidade de leis penais no País que apontam para a hipervalorização do sistema punitivo (BIANCHINI, 2002, p. 81-82).

Com isso, não parece exagero entender que por falta de bases teóricas e racionais claras, a prática da política criminal se limite com mais apego à simples produção legislativa, que vem, sistematicamente, inflacionando o acervo de normas penais e alimentando o sistema penal punitivo. Nesse contexto, caso se considere que a "conduta só pode ser perigosa quando as razões convencem" (JACOBS, 2003, p. 140), a Lei n. 13.654/2018 foi, certamente, fruto do convencimento do Parlamento brasileiro de que o emprego de armas diversas das "de fogo" não representariam perigo para as vítimas do crime de roubo e, da mesma forma, o PLS n. 279/2018, apresentado em data subsequente, procura “(re)convencer" que essa descrita circunstância enseja perigo concreto para suas vítimas.

Logo, a questão do convencimento anteriormente exposta por Günther Jacobs, se considerada no plano da elaboração da política criminal pelo Parlamento, não chega a ser critério ou técnica precedente, mas antes uma postura que tem a ver com a simples admissão ou rejeição de propostas legislativas criminais. Desse modo, a atuação política mais intervencionista nos moldes atualmente praticados, traduz política criminal e a confunde com punitivismo penal, "restringindo a liberdade individual, tudo sob a pretensa finalidade de assegurar a paz social” (FÖPPEL EL HIRECHE, 2004, p. 30).

De um ponto de vista mais persuasivo, se a ação humana é exercício de atividade final, cujo fundamento se baseia em que o homem "pode prever, dentro de certos limites, as possíveis consequências de sua conduta" (WELZEL, 2001, p. 27), é indiscutível que o agente 
que pratica o roubo munido de arma (de fogo, branca, própria ou imprópria), age com a consciência de que poderá infligir dano concreto à incolumidade de suas vítimas. Então, é de se esperar que sua pena seja proporcionalmente mais graduada em face de risco mais intenso decorrente da conduta que protagonizar.

\section{CONSIDERAÇÕES FINAIS}

Alguns aspectos particulares da atividade político-legislativa não encontram justificativa no âmbito da lógica ou mesmo das ciências sociais, como o Direito e a Ciência Política, isso porque a perspectiva do Estado se traduz na pretensão de organização das instituições em um nível minimamente aceitável de coerência e de adesão aos postulados da ordem constitucional, criados e mantidos com o propósito de que todos os indivíduos e as instituições, públicas e privadas, conheçam e possam se orientar segundo a definições postas pela ordem política e jurídica, como vetores de uma sociedade madura, organizada, igualitária e, sistematicamente, orientada por normas objetivas, claras e, preferencialmente, determinadas quanto às suas finalidades.

Para tanto, é preciso que os paradigmas normativos criados pela ordem política sejam indeclinavelmente coerentes com as linhas mestras do Estado, como a democracia e a ordem jurídica. Nesse contexto, a produção da política criminal em face de todos os possíveis arranjos institucionais deve ser um marco referencial de maior credibilidade das instituições e de todos os setores que integram o sistema de justiça criminal. A exemplo do tema em discussão, pôde-se constatar a completa ausência, primeiramente, de técnica legislativa (necessidade, avaliação, impacto, ponderação etc.) para adoção do projeto com o qual foi revogado o inciso $\mathrm{I}$, do $\S 2^{\circ}$, do art. 157, do Código Penal, consistente em não se ter explicitado nenhuma fundamentação, jurídica, política ou sociológica, para se extirpar do ordenamento jurídico o aludido dispositivo legal; em segundo, a existência jurídica do dispositivo revogado por um período superior a 77 anos não foi óbice para a tramitação e aprovação do projeto e sua posterior conversão em lei; em terceiro, a desigualdade de tratamento resultante a partir da edição da Lei n. 13.654/2018 não foi consequência avaliada pelo Parlamento, de modo que, atualmente, seguindo-se à estrita determinação legal, não se pune com o mesmo rigor quem pratica o roubo mediante o emprego de faca, canivete, estilete, pedra, pedaço de madeira, cacos de vidro etc., e quem o pratica com o emprego de armas de fogo, embora se reconheça que o emprego de quaisquer desses artefatos cause o mesmo temor 
às vítimas, além de expô-las ao mesmo nível de perigo quanto à incolumidade física, uma vez que o perigo de agressão física é real e iminente.

No caso dos projetos de leis tomados como referenciais da atividade legislativa (PLS n. 149/2015 e PLS n. 279/2018) não se identificou nenhum critério definido, objetivo e, principalmente, coerente com a decisão do Parlamento em revogar o inciso I, do $\S 2^{\circ}$, do art. 157, do Código Penal, e, subsequentemente, restabelecê-lo mediante a edição de nova lei.

\section{REFERÊNCIAS}

ANDRADE, Vera Regina Pereira de. Horizonte de projeção da política criminal e crise do sistema penal: utopia abolicionista e metodologia minimalista-garantista. In: Seminário Impasses da Política Criminal Contemporânea, Instituto Carioca de Criminologia, Rio de Janeiro, p. 1-20, jun. 2009. Disponível em: <http://www.cnj.jus.br/files/conteudo/arquivo/ 2016/02/6b930b2302bd997668f95a2e8a1efeed.pdf>. Acesso em: 2 jul. 2018.

AROMAA, Kauko. Responsible criminal policy, crime and criminal policy. In: Kriminologijos Studijos, Vilniaus Universiteto Leidykla, p. 77-85, jan. 2014. Disponível em: <http://www.zurnalai.vu.lt/kriminologijos-studijos/article/download/3677/2636>. Acesso em: 2 jul. 2018.

BALLESTEROS, Paulo Rodriguez. Agenda legislativa para a política criminal de alternativas penais: intervenção mínima, desencarceradora e restaurativa. Brasília: Ministério da Justiça, 2016. Disponível em: <http://www.justica.gov.br/seus-direitos/politica-penal/ politicas-2/alternativas-penais-1/arquivos/agenda-legislativa-para-a-politica-de-alternativaspenais.pdf $>$. Acesso em: 2 jul. 2018.

BENAVIDES BENALCÁZAR, Merck Milko; MORALES, María Gabriela Acosta. El principio de oportunidad como mecanismo de política criminal: un estudio exploratorio a partir del criterio de la eficiencia procesal. In: Revista Publicando, v. 4, n. 13, fascículo n. 2, p. 266-282, 2017. Disponível em: <https://www.rmlconsultores.com/revista/index.php/crv/ article/download/849/pdf_614>. Acesso em: 5 jul. 2018.

BIANCHINI, Alice. Pressupostos materiais da tutela penal. São Paulo: Editora Revista dos Tribunais, 2002.

BRASIL. Decreto-Lei n. 2.848, de 7 de dezembro de 1940. Código Penal. Disponível em: <http://www.planalto.gov.br/CCIVIL_03/Decreto-Lei/Del2848.htm>. Acesso em: 29 jun. 2018.

Lei $n$. 13.654, de 23 de abril de 2018. Altera o Decreto-Lei $\mathrm{n}^{\circ} 2.848$, de 7 dezembro de 1940 (Código Penal). Disponível em: <http://www.planalto.gov.br/ccivil_03/_ ato2015-2018/2018/lei/L13654.htm>. Acesso em: 29 jun. 2018. 
Plano Nacional de Política Criminal e Penitenciária 2015. Brasília: Ministério da Justiça, 2015. Disponível em: <http://www.justica.gov.br/seus-direitos/politica-penal/ cnpcp-1/imagens-cnpcp/plano-nacional-de-politica-criminal-e-penitenciaria-2015.pdf >

Acesso em: 2 jul. 2018.

. Senado Federal. Projeto de Lei do Senado n. 279, de 2018. Modifica o Decreto Lei no 2.848, de 7 de dezembro de 1940 - Código Penal, para restabelecer para o crime de roubo a causa de aumento de pena do emprego de arma. Disponível em: <https://legis.senado. leg.br/sdleg-getter/documento?dm=7742111\&ts=1530192646663\&disposition=inline \&ts= $1530192646663>$. Acesso em: 29 jun. 2018.

Senado Federal. Rel. Senador Antonio Anastasia. Relatório Legislativo no Projeto de Lei do Senado n. 149, de 9 de julho de 2015. Disponível em: <https://legis.senado. leg.br/sdleg-getter/documento?dm=3599811\&ts=1529354143974\&disposition=inline \&ts= 1529354143974>. Acesso em: 2 jul. 2018.

Superior Tribunal de Justiça. Sexta Turma. Rel. Min. Maria Thereza de Assis Moura. Agravo de Instrumento no Habeas Corpus n. 432.571 SC, pub. 4/6/2018. Disponível em: $\quad<$ https://ww2.stj.jus.br/processo/revista/documento/mediado/?componente=ATC\& sequencial $=83822738 \&$ num_registro $=201800029152 \&$ data $=20180604 \&$ tipo $=5 \&$ formato $=P D$ F>. Acesso em: 3 jul. 2018.

Supremo Tribunal Federal. Primeira Turma. Rel. Min. Dias Toffoli. Recurso Ordinário em Habeas Corpus n. 120.297 RJ, pub. 3/6/2014. Disponível em: <http://www.stf. jus.br/portal/inteiroTeor/obterInteiroTeor.asp?idDocumento=6006857>. Acesso em: 2 jul. 2018.

BUCCI, Maria Paula Dallari. Fundamentos para uma teoria jurídica das políticas públicas. São Paulo: Saraiva, 2013.

CAMPOS, Marcelo da Silveira. Crime e Congresso Nacional: uma análise da política criminal aprovada de 1989 a 2006. In: Revista Brasileira de Ciência Política, Brasília, n. 15, p. 315-347, set./dez. 2014. Disponível em: <http://www.scielo.br/pdf/rbcpol/n15/0103-3352rbcpol-15-00315.pdf>. Acesso em: 2 jul. 2018.

CARRABINE, Eamonn et al. Criminology: a sociological introduction. 2. ed. London: Routledge, 2009. Disponível em: <https://www.hrstud.unizg.hr/_download/repository/ Eamonn_Carrabine\%2C_Maggy_Lee\%2C_Nigel_South\%2C_Pam_Cox\%2C_Ken_Plummer _Criminology_A_Sociological_Introduction_2009.pdf>. Acesso em: 5 jul. 2018.

D’ÁVILA, Fábio Roberto. Os limites normativos da política criminal no âmbito da ciência conjunta do direito penal. In: Zeitschrift für Internationale Strafrechtsdogmatik, n. 10, p. 485495, 2008. Disponível em: <http://www.zis-online.com/dat/artikel/2008_10_273.pdf>. Acesso em: 2 jul. 2018.

DELMAS-MARTY, Mireille. Os grandes sistemas de política criminal. Tradução Denise Radanovic. Barueri, SP: Manole, 2004. 
FÖPPEL EL HIRECHE, Gamil. A função da pena na visão de Claus Roxin. Rio de Janeiro: Forense, 2004.

FRAGOSO, Heleno Cláudio. Lições de direito penal: parte especial. v. 1. 10. ed. Rio de Janeiro: Forense, 1988.

GARLAND, David. As contradições da "sociedade punitiva": o caso britânico. In: Revista de Sociologia e Política, n. 13, p. 59/80, nov. 1999. Disponível em: <http://www.scielo.br/pdf/ rsocp/n13/a06n13.pdf>. Acesso em: 10 jul. 2018.

Penality and the penal state. In: Criminology, v. 51, n. 3, p. 475-571, jun. 2013. Disponível em: <https://pdfs.semanticscholar.org/221d/6ba1200fc0dc551a30eb79d46dfb55 0b7fea.pdf $>$. Acesso em: 10 jul. 2018.

GARSIDE, Richard. Crime, persistent offenders and the justice gap. In: Crime and Society Foundation, London, p. 5-25, oct. 2004. Disponível em: <https://www.crimeandjustice.org. uk/sites/crimeandjustice.org.uk/files/crime, \%20persistent\%20offenders.publication.pdf $>$.

Acesso em: 2 jul. 2018.

GUTIÉRREZ HINOJOSA, Tomás Darío. Criminología, causa final y política criminal. In: Revista Derecho Penal y Criminología, v. 37, n. 102, p. 13-12, ene./jun. 2016. Disponível em: <https://revistas.uexternado.edu.co/index.php/derpen/article/view/4653/5404>. Acesso em: 5 jul. 2018.

JACOBS, Günther. Fundamentos do direito penal. Tradução André Luís Callegari. São Paulo: Editora Revista dos Tribunais, 2003.

JENNINGS, Will et al. Penal populism and the public thermostat: crime, public punitiveness and publica policy. In: Elections, Public Opinion and Parties Conference, Cardiff University, p. 2-28, sep. 2015. Disponível em: <https://eprints.soton.ac.uk/390589/1/PenalPopulismTher mostat_Governance_Preprint.pdf>. Acesso em: 5 jul. 2018.

KUBICIEL, Michael. Ciencia del derecho penal y política criminal europea. In: Revista Derecho Penal y Criminología, v. 34, n. 97, p. 29-42, jul./dic. 2013. Disponível em: <https:// revistas.uexternado.edu.co/index.php/derpen/article/view/3867/4162>. Acesso em: 5 jul. 2018.

LACEY, Nicola; SOSKICE, David; HOPE, David. Understanding the determinants of penal policy: crime, culture and comparative political economy. In: International Inequalities Institute, London, Working Paper n. 13, p. 4-36, jul. 2017. Disponível em: <http://www.lse. ac.uk/International-Inequalities/Assets/Documents/Working-papers/Working-Paper-13-Under standing-the-Determinants-of-Penal-Policy-crime-culture-and-comparative-politicaleconomy.pdf>. Acesso em: 5 jul. 2018.

MACHADO, Bruno Amaral. Justiça criminal, Estado de Direito e democracia: entre o discurso e as práticas, contradições e desafios. In: (Coord.). Justiça Criminal e Democracia. São Paulo: Marcial Pons; Brasília: Fundação Escola Superior do Ministério Público do Distrito Federal e Territórios, 2013, p. 11-22. 
Justiça criminal: diferenciação funcional, interações organizacionais e decisões. São Paulo: Marcial Pons, 2014.

MATTHEWS, Roger. Beyond "so what?": rediscovering realism. In: Theoretical Criminology, v. 13, n. 3, p. 341-362, aug. 2009. Disponível em: <http://journals.sagepub.com/ toc/tcra/13/3>. Acesso em: 5 jul. 2018.

MIRABETE, Júlio Fabbrini. Código penal interpretado. 3. ed. São Paulo: Atlas, 2003.

MONTEROSSO, Stephen. Punitive criminal justice and policy in contemporary society. In: Queensland University of Technology Law and Justice Journal, v. 9, n. 1, p. 13-25, 2009. Disponível em: <http://www8.austlii.edu.au/cgi-bin/viewdoc/au/journals/QUTLJJ/2009/ 2.pdf $>$. Acesso em: 2 jul. 2018.

MORAES, Maurício Zanoide. Política criminal, constituição e processo penal: razões da caminhada brasileira para a institucionalização do caos. In: Revista da Faculdade de Direito da Universidade de São Paulo, v. 101, p. 403-430, jan./dez. 2006. Disponível em: <https:// www.revistas.usp.br/rfdusp/article/download/67712/70320>. Acesso em: 2 jul. 2018.

MORAIS, José Luís Bolzan de. Políticas públicas e jurisdição constitucional: entre direitos, deveres e desejos. Porto Alegre: Livraria do Advogado Editora, 2016.

MORALES, Ana María. La política criminal contemporánea: influencia en Chile del discurso de la ley y el orden. In: Política Criminal, v. 7, n. 13, p. 94-146, jul. 2012. Disponível em: <http://www.politicacriminal.cl/Vol_07/n_13/Vol7N13A3.pdf >. Acesso em: 5 jul. 2018.

MURDA, Paula Fernanda Vasconcelos Navarro. Políticas públicas: o controle judicial e o papel das funções essenciais à justiça. Curitiba: Editora Prismas, 2015.

QUINTERO OLIVARES, Gonzalo. La derrota de la política criminal y del derecho penal de nuestro tiempo. In: Revista del Instituto de Ciencias Jurídicas, Puebla, México, v. 1, n. 19, p. 46-72, 2007. Disponível em: <https://www.revistaius.com/index.php/ius/article/download/178 /173>. Acesso em: 5 jul. 2018.

RODRIGUEZ, Anabela Miranda. Criminal policy: new challenges, old ways. In: Bulletin of the International Society of Social Defense and Humane Criminal Policy, Milan, Italy, p. 181212, 2003. Disponível em: <http://www.defensesociale.org/revista2003/2003.pdf>. Acesso em: 2 jul. 2018.

SÁNCHEZ, Adriana Romero; VARGAS, Nadia Lizararo; PINZÓN, Lina María Camacho. Crimen y Política Pública Criminal: elementos para la configuración del observatorio de política criminal. Bogotá: Ministerio de Justicia y del Derecho, 2017. Disponível em: <http:// www.politicacriminal.gov.co/Portals/0/documento/CriyPolPubCri.pdf?ver=2017-06-06094951-850>. Acesso em: 5 jul. 2018.

SILVA SÁNCHEZ, Jesús-María. Política criminal y persona. Buenos Aires: Ad-Hoc, 2000.

Rev. de Criminologias e Politicas Criminais | e-ISSN: 2526-0065 | Porto Alegre | v. 4 | n. 2 | p. 1-20 | Jul/Dez. 2018 
SUMALLA, Josep M. Tamarit. Sistema d sanciones y política criminal. In: Revista Electrónica de Ciencia Penal y Criminología, n. 9, p. 6:1-6:40, 2007. Disponível em: <http:// criminet.ugr.es/recpc/09/recpc09-06.pdf>. Acesso em: 5 jul. 2018.

SUXBERGER, Antonio Henrique Graciano. Segurança pública e os dilemas de uma democracia em crise. In: MACHADO, Bruno Amaral (Org.). Justiça criminal e democracia. São Paulo: Marcial Pons; Brasília: Fundação Escola Superior do Ministério Público do Distrito Federal e Território, 2013.

TORRENS, Antonio Carlos. Poder legislativo e políticas públicas: uma abordagem preliminar. In: Revista de Informação Legislativa, Senado Federal, Brasília, a. 50, n. 197, p. 189-204, jan./mar. 2013. Disponível em: <https://www12.senado.leg.br/ril/edicoes/50/197/ ril_v50_n197_p189.pdf>. Acesso em: 2 jul. 2018.

WELZEL, Hans. O novo sistema jurídico-penal: uma introdução à doutrina da ação finalista. Tradução Luís Regis Prado. São Paulo: Editora Revista dos Tribunais, 2001.

WERMUTH, Maiquel Ângelo Dezordi. Política criminal atuarial: contornos biopolíticos da exclusão penal. In: Revista Direito \& Praxis, Rio de Janeiro, v. 8, n. 3, p. 2043-2073, 2017. Disponível em: <http://www.e-publicacoes.uerj.br/index.php/revistaceaju/article/download/ 22314/21391>. Acesso em: 29 jun. 2018. 